\title{
CONCEPÇÕES TEÓRICO-PRÁTICAS DA FORMAÇÃO INICIAL E CONTINUADA DE PRECEPTORES E RESIDENTES DO PROGRAMA DE RESIDÊNCIA MULTIPROFISSIONAL EM SAÚDE DE UM HOSPITAL PÚBLICO DA REGIÃO SUL'1
}

\author{
Elisabeth de Fátima da Silva Lopes² \\ Carmen Lucia Bezerra Machado ${ }^{3}$
}

\section{Resumo}

O artigo aborda as concepções teórico-práticas da formação inicial e continuada de preceptores e residentes de um Programa de Residência Multiprofissional em Saúde. Trata-se de uma pesquisa qualitativa orientada pelo método materialista dialético-histórico. Conclui-se que tanto a formação inicial e continuada dos preceptores e dos residentes, embora o lapso de tempo entre essas, não se diferenciaram, resultando em práticas de formação e de trabalho ainda distantes dos objetivos propostos no Programa de Residência pesquisado. Entretanto, a residência tem estimulado os profissionais a repensarem práticas que expressem a realização do trabalho integrado em saúde.

Palavras-chave: Trabalho; Formação em saúde; Residência multiprofissional.

\section{Resumen}

El artículo aborda las concepciones teórico-prácticas de la formación inicial y continuada de preceptores y residentes de un Programa de Residencia Multiprofesional en Salud. Se trata de una investigación cualitativa orientada por el método materialista dialéctico-histórico. Se concluye que tanto la formación inicial y continuada de los preceptores y de los residentes, aunque el lapso de tiempo entre ellas, no se diferenció, resultando en prácticas de formación y de trabajo aún distantes de los objetivos propuestos en el Programa de Residencia investigado. Sin embargo, la residencia ha estimulado a los profesionales a repensar prácticas que expresen la realización del trabajo integrado en salud.

Palabras clave: Trabajo; Formación en salud; Residencia multiprofesional.

\footnotetext{
${ }^{1}$ DOI: $\underline{\text { https://doi.org/10.22409/tn.15i28.p9644 }}$

${ }^{2}$ Dra. Elisabeth de Fátima da Silva Lopes, pedagoga do Hospital de Clínicas de Porto Alegre. Email: vvitvvit@gmail.com

${ }^{3}$ Dra. Carmen Lucia Bezerra Machado, professora titular da Faculdade de Educação da Universidade Federal do Rio Grande do Sul. E-mail: carmen.machado@ufrgs.br
} 


\section{Introdução}

Entendemos a formação como um processo de aprendizagens e experiências mediatizado por múltiplas determinações e contradições sociais, que produz mudanças singulares no ser social que se forma. Nesse sentindo, Freire menciona que "quem forma se forma e re-forma ao formar e quem é formado forma-se e forma ao ser formado [...]" (1996, p.23). A formação é um processo coletivo.

Ao investigarmos as concepções teórico-práticas da formação inicial e continuada de preceptores e residentes ${ }^{3}$ do Programa de Residência Multiprofissional em Saúde de um Hospital Público da Região Sul nos acercamos de uma figura de linguagem criada por Antonio Gramsci em uma de suas obras, "Cadernos do Cárcere" (2002), denominada de "miscelâneas". Preso político pelo governo fascista, privado de sua liberdade, sem amplo acesso aos saberes constituídos e circulantes no seu tempo, Gramsci constrói seus "Cadernos do Cárcere" nessa materialidade, recebendo em vários momentos de sua construção partes que denominou "Miscelâneas". Este termo que no Dicionário Aurélio de Língua Portuguesa tem o significado de: "Mistura de variadas compilações literárias. Mistura de coisas diversas" (2008, p. 339), para o autor designa conjuntos de informações e ou textos já organizados, mas que não pretendem esgotar o assunto. Utilizamos o termo na combinação destes dois sentidos. Concebendo a formação como um devir, não pretendemos esgotar a temática e, tampouco, a análise sobre a formação inicial e continuada dos sujeitos pesquisados. Os dados podem ser retomados em novas pesquisas desencadeadas a partir deles.

Este artigo é composto pelas miscelâneas de alguns aspectos teóricos e práticos da formação inicial e continuada dos sujeitos da pesquisa, a partir do resgate oral sobre o vivido em suas formações em saúde como algo que continua se constituindo no presente num processo histórico inacabado. Há um lapso de tempo entre as formações iniciais dos preceptores e residentes. Estes após a vigência das atuais Diretrizes Curriculares Nacionais (DCN) para a formação em

\footnotetext{
${ }^{3}$ Preceptores são os profissionais de saúde, contratados do hospital, que orientam e acompanham de modo teórico-prático, os residentes ao longo de toda a formação em serviço. Residentes são os profissionais de saúde, que fazem um curso de especialização latu sensu oferecido por um Programa de Residência em Instituições de saúde.
} 
saúde, publicadas a partir de 2001, e metade dos preceptores antes da vigência dessas Diretrizes. Como uma política pública intersetorial entre o Ministério da Saúde e Ministério da Educação para a formação e desenvolvimento de profissionais da saúde, as DCN têm seu marco regulatório inspirado no Art. 200, inciso III da Constituição Federal (CF) de $1988^{4}$ e suas orientações a partir das proposições da Reforma Sanitária Brasileira $(\mathrm{RSB})^{5}$. Estão inspiradas também na pedagogia do aprender a aprender 6 . Embora esse arcabouço pedagógico, estudos apontam que a formação dos profissionais da saúde realizada nas universidades permanece distante do proposto na RSB. Ceccim observa que as "Instituições formadoras têm perpetuado modelos essencialmente conservadores, centrados em aparelhos e sistemas orgânicos e tecnologias altamente especializadas" (2004a, p. 42).

A pesquisa sobre as concepções teóricas e práticas da formação inicial e continuada dos preceptores e residentes tornou-se imprescindível no estudo da repercussão daquelas nas práticas desenvolvidas no programa investigado no sentido de oferecer contribuições para o repensar dessas práticas.

\footnotetext{
${ }^{4} \mathrm{CF} / 88$ - Art. 200 - Ao sistema único de saúde compete, além de outras atribuições, nos termos da lei: III - ordenar a formação de recursos humanos na área de saúde. Disponível em: http://www.planalto.gov.br/ccivil_03/constituicao/constituicaocompilado.htm. Acessado em 23-0916.

${ }^{5}$ O texto das DCN menciona como objetivo: "permitir que os currículos propostos possam construir perfil acadêmico e profissional com competências, habilidades e conteúdos, dentro de perspectivas e abordagens contemporâneas de formação pertinentes e compatíveis com referências nacionais e internacionais, capazes de atuar com qualidade, eficiência e resolutividade, no Sistema Único de Saúde (SUS), considerando o processo da Reforma Sanitária Brasileira ( grifo nosso)" (BRASIL, 2001).

${ }^{6}$ Em entrevista à Revista Rubra, Demerval Saviani ao ser perguntado sobre quem seriam os defensores da pedagogia do aprender a aprender, referiu que essa pedagogia tem sido a grande referencia dominante, presente nos documentos oficiais internacionais reproduzidos em diversos países. As Diretrizes Curriculares Nacionais para os Cursos da Saúde constituem um dos expressivos exemplos da reprodução da pedagogia citada. Saviani fala na revista que: "O Relatório Jacques Delors das Nações Unidas sobre educação para o século XXI tem como eixo essa orientação do "aprender a aprender" e os países reproduzem isso nas suas políticas educativas. É uma pedagogia que tem origem na escola nova, no construtivismo de Piaget, que estava apoiado no keynesianismo. Agora foi recuperada, no contexto político do neoliberalismo. A ideia é que todo o ambiente é educativo - aprende-se em diferentes lugares, em diferentes circunstâncias e também na escola. Em razão disso, a visão rígida foi superada em benefício de uma sociedade flexível em que nada se pode prever. A escola não pode formar para 5 ou 10 anos. Não se sabe como vai ser o futuro que está em constante mudança. Portanto, a escola não deve ensinar algo mas apenas aprender "[...] No Brasil introduzem parâmetros curriculares nos temas 'transversais' - é como se os temas não fossem objeto desta ou daquela disciplina mas atravessam todo o currículo - educação cívica, moral, ambiental, sexual". Disponível em: http://www.revistarubra.org/?page_id=171. Acessado em 15/02/17.
} 


\section{Método}

Este artigo resultou de parte de uma pesquisa qualitativa realizada sob a orientação do método materialista dialético-histórico. O materialismo dialético tem sido considerado como a filosofia do marxismo. Nessa concepção metodológica, a realidade material é estudada e interpretada como essencialmente contraditória e em permanente transformação. Conforme o dicionário do pensamento Marxista, "o conflito dos contrários faz avançar a realidade num processo histórico de transformação progressiva e constante" (BOTTOMORE, p. 259, 2001). O materialismo histórico, por sua vez, constitui a parte da filosofia marxista que aplica os princípios do materialismo dialético no estudo da vida social. Para Friedrich Engels (1981) é uma visão do desenvolvimento da história que busca a causa final e a força motriz que move os acontecimentos históricos significativos no desenvolvimento econômico da sociedade, nas transformações dos modos de produção, na divisão e na luta de classes.

A coleta de informações se deu pela história oral temática sobre a formação inicial e continuada dos preceptores e residentes do programa de residência pesquisado. Para a definição da amostra foi estabelecido, como critério prévio os entrevistados, serem egressos de graduação em saúde, participantes do programa entre 2010 a 2014.

Foram realizadas entrevistas com seis residentes e seis preceptores, representantes dos seis núcleos profissionais do programa, ou seja, com educadores físicos, assistentes sociais, nutricionistas, enfermeiros, farmacêuticos e psicólogos, integrantes das Áreas de Concentração do Programa na ocasião: Adulto Crítico, Saúde Mental, Saúde da Criança, Controle de Infecção Hospitalar e Onco- Hematologia. Elaboramos, portanto, dois roteiros de entrevista. Um para o segmento de preceptores, outro para o segmento de residentes.

O estudo foi aprovado no Comitê de Ética em Pesquisa da instituição, preservada sua identificação.

As possibilidades da análise e resultados foram organizadas por meio da realização de entrevistas semiestruturadas aprofundadas. Segundo Triviños (2001) essas constituem uma das "ferramentas" utilizadas pela pesquisa qualitativa para atingir seus objetivos. 
Lançamos mão da "história oral temática", uma vez que focamos a escuta dos sujeitos desta pesquisa nos temas que constituíram o processo histórico de suas formações em saúde. A história oral é definida como

um método de pesquisa (histórica, antropológica, sociológica etc.) que privilegia a realização de entrevistas com pessoas que participaram de, ou testemunharam, acontecimentos, conjunturas, visões de mundo, como forma de se aproximar do objeto de estudo (ALBERTI, 2001, p.18).

O emprego da história oral gera a possibilidade da recuperação de informações que não se encontram em documentos, tais como: experiências pessoais, concepções, vivências de um acontecimento na prática.

Meihy aponta a história oral temática como uma modalidade da história oral e argumenta que essa abordagem busca "a verdade de quem presenciou um acontecimento ou pelo menos dele tenha alguma versão que seja discutível ou contestatória" (1996, p.41). Nesse sentido, necessitávamos ouvir dos sujeitos da pesquisa o vivido em seu passado distante e recente, a recuperação de suas histórias orais sobre o tema - formação inicial e continuada em saúde, por isso histórias orais temáticas. Entretanto, essas histórias só abrangeriam o propósito de um estudo de caso qualitativo, se fossem acrescidas de uma gama de informações provenientes de outras fontes, analisadas a partir de uma interpretação dialética. Cada entrevistado, ao narrar sua formação e práticas profissionais, recuperou nesses aspectos a materialidade de sua existência, circundada pelos mais variados contextos sociais.

Foram descritas as concepções dos sujeitos sobre educação em saúde, os aspectos facilitadores e dificultadores de suas formações e práticas profissionais, suas percepções sobre os aspectos pedagógicos da formação e referenciais teóricos que a compuseram, além de suas representações sobre os âmbitos estruturais e conjunturais que produziram a materialidade de suas graduações.

\section{Miscelâneas da formação em saúde}

No sentido de apreendermos as contradições que compõem a realidade que produziu e produz as formações dos trabalhadores da saúde foi necessário percorrermos os movimentos que resultaram em mudanças estruturais expressivas e decisivas politicamente no âmbito da saúde e da educação em 
saúde entre essas, a Reforma Sanitária Brasileira e mais tarde a criação do SUS. Frigotto diz que nos anos 80 , tanto a luta pela reforma na saúde, quanto a desenvolvida no campo educacional fazem parte de um "contexto mais amplo de mudanças societárias estruturais, de forte determinação política, de mobilização e luta da sociedade por seus direitos sociais e subjetivos (2008, s.p.).

Entre esses acontecimentos, a 8 ${ }^{\text {a }}$ Conferência Nacional de Saúde (CNS), em 1986, constituiu um movimento importante de ativações de mudanças no modo de pensar a saúde no Brasil. Mais de cinco mil representantes de todos os segmentos da sociedade civil problematizaram acerca de um novo entendimento de saúde para o país, como direito do cidadão e dever do Estado. O conteúdo textual e político produzido na $8^{\text {a }}$ CNS resultou no nascimento do Sistema Único de Saúde (SUS), garantido na CF de 1988 e regulamentado pelas Leis 8.080/90 e $8.142 / 90^{7}$ que determinam os princípios legais para o funcionamento de sua rede

\footnotetext{
${ }^{7}$ A Lei 8.080 de 19 de setembro de 1990: Dispõe sobre as condições para a promoção, proteção e recuperação da saúde, a organização e o funcionamento dos serviços correspondentes e dá outras providências. A Lei 8.142 de 28 de dezembro de 1990: Dispõe sobre a participação da comunidade na gestão do Sistema Único de Saúde (SUS) e sobre as transferências intergovernamentais de recursos financeiros na área da saúde e dá outras providências.

${ }^{8}$ A Lei $8080 / 1990$ no Art. $6^{\circ}$, inciso XI, $\S 1^{\circ}$, define Vigilância Sanitária como "um conjunto de ações capazes de eliminar, diminuir ou prevenir riscos à saúde e de intervir nos problemas sanitários decorrentes do meio ambiente, da produção e da circulação de bens e da prestação de serviços de interesse da saúde, abrangendo: I - o controle de bens de consumo que, direta ou indiretamente, se relacionem com a saúde, compreendidas todas as etapas de processo, da produção ao consumo; II - o controle da prestação de serviços que se relacionam direta ou indiretamente com a saúde" (BRASIL, p. 10, 2002).

${ }^{9}$ A Lei 8080/1990 no Art. 6으, inciso XI, § 20 define a vigilância epidemiológica como: um conjunto de ações que proporcionam o conhecimento, a detecção ou prevenção de qualquer mudança nos fatores determinantes e condicionantes de saúde individual ou coletiva, com a finalidade de recomendar e adotar as medidas de prevenção e controle das doenças ou agravos (BRASIL, 1990).

${ }^{10}$ A Lei 8080/1990 no Art. 6ํ, inciso XI, § 3o define a saúde do trabalhador como: um conjunto de atividades que se destinam, através das ações de vigilância epidemiológica e vigilância sanitária, à promoção e proteção da saúde dos trabalhadores, assim como visa à recuperação e reabilitação da saúde dos trabalhadores submetidos aos riscos e agravos advindos das condições de trabalho, abrangendo: I - assistência ao trabalhador vítima de acidentes de trabalho ou portador de doença profissional e do trabalho; II - participação, no âmbito de competência do Sistema Único de Saúde (SUS), em estudos, pesquisas, avaliação e controle dos riscos e agravos potenciais à saúde existentes no processo de trabalho; III - participação, no âmbito de competência do Sistema Único de Saúde (SUS), da normatização, fiscalização e controle das condições de produção, extração, armazenamento, transporte, distribuição e manuseio de substâncias, de produtos, de máquinas e de equipamentos que apresentam riscos à saúde do trabalhador; IV- avaliação do impacto que as tecnologias provocam à saúde; $\mathrm{V}$ - informação ao trabalhador e à sua respectiva entidade sindical e às empresas sobre os riscos de acidentes de trabalho, doença profissional e do trabalho, bem como os resultados de fiscalizações, avaliações ambientais e exames de saúde, de admissão, periódicos e de demissão, respeitados os preceitos da ética profissional; VI - participação na normatização, fiscalização e controle dos serviços de saúde do trabalhador nas instituições e empresas públicas e privadas; VII - revisão periódica da listagem oficial de doenças originadas no processo de trabalho, tendo na sua elaboração a colaboração das entidades sindicais; e VIII - a
} 
assistencial. É orientado pelo atendimento integral, pela priorização das ações preventivas, entre essas, as ações de vigilância sanitária ${ }^{8}$, vigilância epidemiológica ${ }^{9}$, saúde do trabalhador ${ }^{10}$, sem o descuido das ações assistenciais, pelo controle da população sobre os serviços oferecidos e pela descentralização, mas com direção única em cada esfera de governo.

Em meio aos cenários do final da década de setenta e pós-criação do SUS os preceptores e residentes realizaram suas formações em saúde. Os preceptores entre 1974 e 2003 e os residentes entre 2008 e 2010.

Nessa materialidade, a história oral sobre alguns aspectos das formações dos sujeitos de pesquisa vai sendo tecida ao longo de suas memórias de um tempo longínquo para alguns e recente para outros:

Preceptor Enfermeiro: A minha formação só transmitiu conhecimentos e foi com muito pouco debate, pouca atuação do aluno. Não me preparou para trabalhar na lógica do SUS. Durante os meus vinte e sete anos trabalhando num hospital público, ninguém me preparou para trabalhar no SUS.

Residente Nutricionista: A graduação na universidade pública em que me formei foi muito voltada para clínica, não me preparou para atuar no SUS. E para trabalhar com o SUS eu tive somente uma cadeira que abordava a parte de nutrição e da saúde comunitária. Só que o modo como eles abordaram na faculdade não foi atrativo. É muito complicado tu discutires só em cima de lei e ler lei, tu não te motivas. É uma cadeira que ninguém gosta. Então é muito difícil, por exemplo, alguém querer seguir a área de saúde comunitária ou saúde da família. Não instiga a curiosidade. Eles têm uma visão muito hospitalar.

A primeira narrativa acima trata das vivências da formação inicial de um preceptor, que concluiu seu curso há mais de 20 anos. A segunda relata as vivências de um residente que realizou seu curso a partir das atuais DCN. Apesar da distância entre uma e outra os dois realizaram suas formações na perspectiva biomédica, ainda dominante. Sobre esse aspecto, Ceccim e Feuerwerker referem:

garantia ao sindicato dos trabalhadores de requerer ao órgão competente a interdição de máquina, de setor de serviço ou de todo ambiente de trabalho, quando houver exposição a risco iminente para a vida ou saúde dos trabalhadores (BRASIL, 1990). 
O modelo pedagógico hegemônico de ensino é centrado em conteúdos, organizado de maneira compartimentada e isolada, fragmentando os indivíduos em especialidades da clínica, dissociando conhecimentos das áreas básicas e conhecimentos da área clínica, centrando as oportunidades de aprendizagem da clínica no hospital universitário, adotando sistemas de avaliação cognitiva por acumulação de informação técnico-científica padronizada, incentivando a precoce especialização, perpetuando modelos tradicionais de prática em saúde (CECCIM; FEUERWERKER, 2004a, p. 1402).

A permanência ativa do modelo hegemônico na formação dos trabalhadores da saúde, para além das propostas mais progressistas materializadas nos anos dois mil, é fortemente vivificada pelas influências internacionais do Banco Mundial (BM) e da Organização das Nações Unidas para a Educação, a Ciência e Cultura (UNESCO). Segundo Melo, "A formação do trabalhador [..] vai se modificando nas propostas do BM e da UNESCO, na direção da conformação a estas novas necessidades para o trabalhador polivalente e flexível" ( 2004, p.190).

A polivalência, muito em voga atualmente, propõe um trabalhador crítico, reflexivo, como apontam os textos das atuais $\mathrm{DCN}^{11}$ com diversificadas "competências, habilidades e atitudes" exigidas como performance nos postos de trabalho.

Essas Diretrizes mediadas por um terreno de contradições, além de terem absorvido as características apontadas por Melo, em seu reverso, buscaram subsídios nos princípios do SUS, propondo um perfil de formação generalista, humanista, crítica e reflexiva. Em suas propostas ficam visíveis as marcas das políticas públicas de saúde, de educação e do projeto de sociabilidade neoliberal

\footnotetext{
${ }^{11} \mathrm{O}$ texto das DCN do Curso de Graduação em Enfermagem aponta no perfil do formando egresso/profissional em enfermagem, entre outras proposições, a formação: "generalista, humanista, crítica e reflexiva. Profissional qualificado para o exercício de Enfermagem, com base no rigor científico e intelectual e pautado em princípios éticos. Capaz de conhecer e intervir sobre os problemas/situações de saúde-doença mais prevalentes no perfil epidemiológico nacional, com ênfase na sua região de atuação, identificando as dimensões biopsicossociais dos seus determinantes. Capacitado a atuar, com senso de responsabilidade social e compromisso com a cidadania, como promotor da saúde integral do ser humano". Disponível em: http://portal.mec.gov.br/cne/arquivos/pdf/Enf.pdf, acessado em 24-08-13. (O grifo no texto é meu). $\mathrm{O}$ texto das DCN do Curso de graduação em Nutrição também refere no perfil do formando egresso/profissional em Nutrição: "a formação generalista, humanista e crítica". Disponível em: http://portal.mec.gov.br/cne/arquivos/pdf/Nutr.pdf, acessado em 24-08-13.
} 
dos organismos internacionais resultantes das relações de poder e dos embates das forças contraditórias presentes na sociedade brasileira.

No entendimento de Ito (2006), se a proposta das DCN fosse bem trabalhada poderia trazer resultados positivos à formação no sentido de atender às reais necessidades dos problemas de saúde. No entanto, a autora adverte que ainda existem muitas contradições que impedem uma mudança efetiva na formação, algumas delas produzidas pelos próprios docentes, tais como: "a pouca reflexão sobre a docência, o distanciamento dos serviços de saúde com o reforço à clássica dicotomia entre o pensar e o fazer, além do autoritarismo, fragmentação e tecnicismo" (ITO, 2006, p. 574).

Nesse cenário, os programas de Residência Multiprofissionais em Saúde, espalhados pelo Brasil, inserem-se como uma política pública, que traz em suas proposições o empenho de dar conta do trabalho integrado e dos princípios do SUS e, de certo modo, desenvolver na formação em serviço o que não foi praticado, durante a formação graduanda. Constitui-se de um curso de especialização lato sensu com duração de 24 meses desenvolvidos em instituições de saúde. A formação em serviço, nessa modalidade, segue as determinações da CF de 1988, art. 200, incisos III e IV ${ }^{12}$, da Lei 8.080/90, art. 6, inciso III e art. $15^{13}$ e, em específico, da Lei 11.129/2005, art. $13^{14}$ que cria o Programa de Residência para as demais profissões da saúde, excetuando a área da medicina que desde 1977 já possui essa modalidade de ensino.

Contraditoriamente ao que almejam, as residências multiprofissionais são propostas de especializações que, se levadas na lógica dominante da formação

\footnotetext{
${ }^{12}$ Constituição Federal do Brasil de 1988 - Art. 200: Ao sistema único de saúde compete, além de outras atribuições, nos termos da lei: inciso III - ordenar a formação de recursos humanos na área de saúde; inciso IV - participar da formulação da política e da execução das ações de saneamento básico.

${ }^{13}$ Lei 8.080 de 1990: Art. 6º Estão incluídas ainda no campo de atuação do Sistema Único de Saúde (SUS): inciso III - a ordenação da formação de recursos humanos na área de saúde; Art.

15. A União, os Estados, o Distrito Federal e os Municípios exercerão, em seu âmbito administrativo, as seguintes atribuições: inciso I - definição das instâncias e mecanismos de controle, avaliação e de fiscalização das ações e serviços de saúde.

${ }^{14}$ Lei 11.129 de 2005: Art. 13. Fica instituída a Residência em Área Profissional da Saúde, definida como modalidade de ensino de pós-graduação lato sensu, voltada para a educação em serviço e destinada às categorias profissionais que integram a área de saúde, excetuada a médica Art. 14. Fica criada, no âmbito do Ministério da Educação, a Comissão Nacional de Residência Multiprofissional em Saúde - CNRMS, cuja organização e funcionamento serão disciplinados em ato conjunto dos Ministros de Estado da Educação e da Saúde.
} 
em saúde, poderão aprofundar ainda mais o que criticam em relação à formação nas residências médicas que seguem, prioritariamente, o modelo biomédico com ênfase em especializações e superespecializações, como menciona Pustai (2006), ao analisar a medicina científica moderna.

Além da residência multiprofissional, existem programas que buscam aproximar a formação aos eixos orientadores do trabalho em saúde necessário ao fortalecimento do SUS. Entre esses, destacamos o Programa de Educação pelo Trabalho para a Saúde, o PET-Saúde ${ }^{15}$ e o Programa Nacional de Reorientação da Formação Profissional em Saúde - o Pró Saúde ${ }^{16}$. Estes têm como balizadores propostas de formação que vislumbrem a produção de conhecimentos e práticas em cenários estratégicos do sistema de saúde, além da tentativa de darem concretude às DCN para os Cursos de Graduação em Saúde. No entanto, mesmo

\footnotetext{
${ }^{15}$ Conforme referido no portal da Saúde o Programa de Educação pelo Trabalho para a Saúde (PET-Saúde) é regulamentado pela Portaria Interministerial № 421, de 03 de março de 2010, disponibilizando bolsas para tutores, preceptores (profissionais dos serviços) e estudantes de graduação da área da saúde. Tem como objetivo geral: propiciar a formação de grupos de aprendizagem tutorial em áreas estratégicas para o SUS com a pretensão de qualificar os profissionais da saúde em serviço, bem como de iniciação ao trabalho e vivências dirigidos aos estudantes das graduações em saúde, de acordo com as necessidades do SUS. Tem como objetivos específicos: facilitar o processo de integração ensino-serviço-comunidade; Institucionalizar as atividades pedagógicas dos profissionais dos serviços de saúde; Valorizar estas atividades pedagógicas; Promover a capacitação docente dos profissionais dos serviços; Estimular a inserção das necessidades do serviço como fonte de produção de conhecimento e pesquisa na universidade; Incentivar o ingresso de profissionais do serviço na carreira docente. Expectativas do PET- Saúde: fortalecer a integração ensino-serviço-comunidade; a qualificação/fortalecimento da Atenção Básica em Saúde e da Vigilância em Saúde; o desenvolvimento de planos de pesquisa em consonância com áreas estratégicas de atuação da Política Nacional de Atenção Básica em Saúde e da Vigilância em Saúde; a constituição de Núcleos de Excelência Clínica Aplicada à Atenção Básica em Saúde; o estímulo para a formação de profissionais de saúde com perfil adequado às necessidades e às políticas públicas de saúde do país; a publicações e participação dos professores tutores, preceptores e estudantes em eventos acadêmicos; o desenvolvimento de novas práticas de atenção e experiências pedagógicas, contribuindo para a reorientação da formação e implementação das Diretrizes Curriculares Nacionais dos cursos de graduação da área da saúde; e a satisfação do usuário SUS. Disponível em: http://portal.saude.gov.br/portal/saude/profissional/area.cfm?id_area=1597. Acessado em: 11/06/12.

${ }^{16}$ O Programa Nacional de Reorientação da Formação Profissional em Saúde (Pró-Saúde) foi instituído pelo Ministério da Saúde, por meio da Secretaria de Gestão do Trabalho e da Educação na Saúde (SGTES), em parceria com a Secretaria de Educação Superior (SESU) e com o Instituto Nacional de Estudos e Pesquisas Educacionais Anísio Teixeira (INEP), do Ministério da Educação (MEC), e com o apoio da Organização Pan-Americana da Saúde (OPAS). Tem como objetivo a integração ensino-serviço, visando à reorientação da formação profissional, assegurando uma abordagem integral do processo saúde-doença. Tem como estratégias: a articulação entre as Instituições de Ensino Superior e o servidor público de Saúde, a potencialização de respostas às necessidades concretas da população brasileira, mediante a formação de recursos humanos, a produção do conhecimento e a prestação dos serviços com vistas ao fortalecimento do SUS. Disponível em: http://prosaude.org/not/prosaude-maio2009/proSaude.pdf. Acessado em 11/06/13.
} 
com essas iniciativas ainda não sentimos a repercussão esperada por tais programas.

A formação dos profissionais por meio do PET Saúde e do Pró Saúde, de modo geral hospitalocêntrica, ainda está subsumida pela lógica biomédica do cuidado, centrada no médico, no procedimento e, marcadamente, fragmentada nas relações entre os profissionais. Com algumas exceções, vislumbram-se práticas em saúde com processos e fluxos aproximados da lógica da clínica ampliada, que leva em consideração os aspectos preconizados pelos princípios do SUS e a perspectiva do cuidado centrado no paciente. Nesse sentido, Aguiar, Nery e Peixoto ao relatarem uma experiência derivada de um PET-Saúde, implantado na Universidade de Brasília e inserido na realidade da comunidade do Paranoá-DF, durante o período 2009-2010, indicam alguns aspectos dificultadores, entre outros, para o sucesso efetivo desse programa:

\begin{abstract}
Ausência de um secretariado dentro da Regional de Saúde para assuntos específicos do PET atrasam o desenvolvimento de atividades. A não fixação de equipe de gestores locais gera uma necessidade de frequentes repactuações, havendo, muitas vezes, falta de investimentos da Secretaria de Saúde em equipamentos básicos para a realização das atividades. As dificuldades também estão presentes dentro da própria Universidade, por intermédio de um baixo apoio da direção (AGUIAR et al., 2010, p.682).
\end{abstract}

Ao problematizarmos o conceito ampliado de saúde, pensado na $8^{\underline{a}} \mathrm{CNS}$, contrário ao entendimento de que a saúde é a simples ausência de enfermidade, ou "um completo estado de bem-estar físico, mental e social (conceito da Organização Mundial de Saúde - OMS), observa-se que mesmo com o propósito de buscar a superação da tradição higienista e curativa por meio da determinação social da doença e de propor o rompimento com o conceito da OMS caracterizado na visão de Dejours (1986) e Caponi (1997) como utópico ou subjetivista, o que presenciamos, no dia-a-dia da formação em saúde, são pequenas e tímidas mudanças periféricas que não provocam rupturas no modelo hegemônico. Apesar do mérito do conceito ampliado de saúde ter articulado a formação aos aspectos sociais, tal providência "não pode ser entendida como um meio e um instrumento de transformação da sociedade como um todo, como o eixo principal e norteador das lutas de mudanças da sociedade" (LUNARDI,1999, p. 29).

A compreensão ampliada da saúde, portanto, requer a convicção de que as possibilidades de transformações da sociedade estejam aliadas a rupturas de 
aspectos estruturais e conjunturais da ordem capitalista que não se resumem às resoluções encaminhadas somente no campo da saúde. Este é apenas um entre tantos campos que, dialeticamente, se mediatizam no metabolismo da sociedade. Nos caminhos da investigação proposta, as falas abaixo evidenciam a formação positivista, pautada pela lógica dominante nas diversas profissões com algumas mudanças na formação do assistente social, conforme referida pela preceptora:

\begin{abstract}
Residente nutricionista - Nos campos de estágio que eu fiz em hospitais públicos não é explorado o fato de sermos profissionais do SUS, isso não é abordado, não é trabalhado ter um olhar integral do paciente. Os estágios me ajudaram mais na logística como profissional, sabe, tu aprenderes o jeito que tu abordas o paciente e o que podes fazer no atendimento individual, mas nada conectado com o SUS.
\end{abstract}

Preceptor assistente social - Eu faço parte de uma formação positivista. Nos anos 70 a nossa faculdade seguia o modelo do Serviço Social americano. Durante muito tempo a área da saúde seguia o modelo biomédico. Em meados dos anos 80, a associação brasileira de ensino e pesquisa na área da assistência social começou a fazer toda uma revisão para criar no Serviço Social um movimento de reconceituação que rompe com a linha positivista, funcionalista, mas nem todas as faculdades estão comprometidas com isso.

Segundo Couto o atual currículo enfatiza o Serviço Social como profissão orientada pela teoria social crítica, tendo seu pluralismo assegurado como valor (2004). Por outro lado, mesmo que desfigurado pelo MEC, quando chancelado legalmente em 2001, a sua origem continua sendo um marco ético-político para a formação em Serviço Social.

Por outro lado, embora as mudanças relatadas pela assistente social, formada nos anos setenta, tenham rompido com o ideário biomédico, sobretudo, pelas próprias peculiaridades do seu campo de atuação, a narrativa abaixo de uma residente, recentemente graduada, vai, em parte, de encontro à efetividade dessas mudanças no âmbito da formação inicial:

Residente Assistente Social - A minha graduação na verdade não me preparou para eu trabalhar no SUS. Na grade curricular do serviço social havia uma disciplina de políticas públicas uma vez por semana em seis meses, onde víamos as três políticas que compõe a seguridade social do cidadão no Brasil e a respectiva bibliografia que eu e minhas colegas não dávamos conta de ler em razão de estudarmos à noite e trabalhar de dia em outro setor 
fora do serviço social. O peso da minha formação foi voltado para a assistência social. Essa disciplina foi a única na qual tive contato com o SUS.

Essa residente realizou sua graduação numa universidade privada no turno da noite. É importante referir o quanto os cursos noturnos, única possibilidade para os trabalhadores que não dispõem de turnos livres, são, de modo geral, os responsáveis pela formação de grande parte do contingente dos trabalhadores. As condições para experiências de estágio são reduzidas e no caso do Serviço Social restam as atividades pontuais de assistência social tais como: albergues, plantões noturnos nos serviços assistenciais oferecidos pelo Estado ou Organizações Não Governamentais (ONGS), trabalhos voluntários, entre outros. Na sequência de sua narrativa a residente destaca essa questão:

Residente Assistente Social - Na minha graduação eu vivia um dilema, porque eu não tinha experiência como assistente social, tinha apenas a teoria. As opções para quem fazia curso noturno e trabalhava de dia seria realizar o estágio à noite e a única alternativa oferecida era nos albergues ou no Departamento Médico Legal.

O curso noturno realizado pela residente manteve-se distante da apropriação das mudanças curriculares promovidas nos anos noventa pela Associação Brasileira de Ensino de Serviço Social e pelo Centro de Pesquisa e Documentação em Serviço Social (MACIEL, 2006).

A década de noventa como reduto das políticas neoliberais de mercado, da regressão de direitos e da flexibilização das conquistas trabalhistas, ofereceu 0 terreno fértil para a afirmação de uma concepção de formação do profissional fragmentada e precarizada. Nesse horizonte "embora sob formas mais sofisticadas, continuam a servir eficientemente aos interesses das várias frações do capital" (COUTINHO, 2005, p. 13).

A proposta neoliberal de educação e a consequente proliferação de cursos aligeirados e massificados de ensino superior limitam as proposições das reformas curriculares, pensadas no final dos anos setenta e anos oitenta, motivadas pela necessidade de reestruturação do processo de trabalho em saúde e pela premente modificação de seu modelo assistencial. Frigotto acentua que nos anos noventa: "A dimensão certamente mais profunda e de consequências mais graves no plano do desmonte da esfera pública foi a privatização do 
pensamento pedagógico" (2006, p. 46). Essa dimensão é sentida fortemente na saúde, como podemos observar na fala de mais um sujeito ao referir-se sobre sua formação inicial realizada numa instituição privada, ao final da década de noventa:

Preceptor psicólogo - A minha formação como psicóloga foi prioritariamente clínica e me detive muito nisso. A minha faculdade priorizava a psicanálise. Entre as disciplinas no curso de psicologia, a de psicologia social trabalhou alguma coisa voltada para as políticas, mas muito pouco sobre o SUS.

A narrativa do preceptor revela a desconexão da formação em relação à apropriação dos fundamentos do SUS. Em igual medida a fala do residente, graduado em 2009 numa universidade pública, não foge tanto da realidade do preceptor de psicologia formada dez anos antes. Mesmo após 21 anos dos atuais 27 de existência do SUS a formação ainda se realiza, hegemonicamente, na lógica médico-centrada, medicalizante, biomédica e da especialidade:

\begin{abstract}
Residente farmacêutico - A formação inicial dos profissionais ainda é para atuar exatamente no enfoque biomédico do hospital. A graduação não forma o profissional para o SUS, forma o profissional para resolver os problemas da profissão. Os profissionais que estão dando aulas para nós, na residência, ainda são formados nessa lógica. Eles estão conseguindo dar aulas na perspectiva do SUS só no teórico. Na prática ainda não conseguiram implementar as propostas, pois eles também estão aprendendo junto conosco. As tentativas de mudança ocorrem, só que às vezes acabam caindo no modelo atual do hospital.
\end{abstract}

As demais narrativas, citadas a seguir, configuram um panorama no mesmo sentido. O primeiro sujeito formado em 2010, o segundo em 2002, o terceiro em 2003 e o quarto em 1991 caminham na mesma direção. Por outro lado, algumas trajetórias que deram sentido a uma formação ampliada para a atuação na saúde, na perspectiva dos fundamentos do SUS, foram propiciadas pelas experiências de vida dos sujeitos, pelas iniciativas pessoais, como assinalado pelas narrativas do residente de farmácia e do preceptor graduado em Educação Física:

Residente farmacêutico - Eu tive contato com o SUS, porque eu procurei estágios na rede básica de saúde. Ali eu tive contato com a rede, com os pacientes. Eu queria ter um pouco de experiência, de contato com o paciente. Apesar de ser farmacêutica, que é um profissional que tem bastante contato com o paciente, a universidade não proporcionava tal contato. Era um estágio extra, fora da faculdade, por minha vontade, eu que fui atrás. 
Preceptor nutricionista - A minha graduação em nutrição, em 2002, não me preparou em nada para trabalhar no SUS. O que tínhamos muito era aula sobre conhecimento específico da nutrição.

Preceptor educador físico - As disciplinas da graduação não tocavam nessa questão do atendimento do educador físico na saúde, na questão da formação para o SUS, não contribuíram para eu entender o sistema. O que ajudou foram as minhas experiências de vida.

Preceptor assistente social - A minha formação em serviço social não me preparou para atuar no SUS. Tive uma formação acadêmica mais direcionada para a questão teórica do serviço social. Não eram trabalhadas as questões do SUS.

No movimento dialético expresso nas falas acima, a formação em saúde, fomentada a partir do ideário proposto pela RSB, acabou sucumbindo mediante as articulações hegemônicas da academia; às produções intelectuais em série, que apesar de refletirem a necessidade de mudanças não apontam caminhos efetivos para tal; aos projetos do Ministério de Educação e da Saúde, desvirtuados dos princípios do sistema; e às posições das Câmaras Técnicas das diversas profissões, rotineiramente defensoras de seus interesses corporativistas.

Nesse sentido Gramsci alerta sobre o equívoco do pensamento corporativo, tipicamente burguês (2002, p. 239). O corporativismo das profissões da saúde dificultou, sobremaneira, a concretização do projeto coletivo de saúde

pensado na RSB. A formação do trabalhador da saúde do ponto de vista produtivo falou mais alto, as incursões "hegemônico-pedagógicas" como expõe Coutinho, ao prefaciar o livro de Neves, perpetuam a busca do consenso no rumo da satisfação dos interesses do capital (2005, p.12). O curso de medicina é um exemplo expressivo quando se observa em seu currículo o leque de opções de áreas de atuação oferecidas. Os graduandos detêm suas opções pelas áreas que

Ihes trarão um retorno financeiro mais elevado em suas promissoras carreiras, ficando a área da atenção primária em última opção. Reproduzindo essa lógica da formação médica, os demais profissionais da área da saúde, sobretudo, a enfermagem, a nutrição, a farmácia, a fisioterapia, a psicologia também privilegiam o seu lócus de trabalho nos níveis de atenção secundário e terciário. Prioritariamente, suas práticas de estágio concentram-se em hospitais, com raras 
exceções. As falas a seguir relatam esta questão da formação costumeiramente hospitalocêntrica:

Preceptor de farmácia - Eu peguei o currículo antigo em que a gente se formava e fazia especialização. Nenhuma disciplina me preparou para o entendimento do SUS. Os estágios também não. Fiz a maioria no Hospital.

Preceptor de nutrição - Os meus estágios foram a maioria no hospital na área da pediatria e materno-infantil. E depois de formada eu fiz um aperfeiçoamento também em Hospital. Os estágios nos hospitais não me proporcionaram uma ideia do SUS. As supervisoras do estágio não davam orientações sobre o SUS.

$\mathrm{Na}$ organização hierarquizada do sistema de saúde ${ }^{17}$, a atenção primária representa o grau dos serviços de menor complexidade e maior frequência, onde se realizam cuidados preferencialmente de promoção e prevenção à saúde, nível considerado de baixo custo pela medicina tradicional. A lógica dessa organização acabou, contraditoriamente, indo de encontro ao princípio da integralidade, com a consequente fragmentação do sistema. Embora a Portaria № 648/GM de 28 de março de $2006^{18}$ que institui a Política Nacional de Atenção Básica, esteja teoricamente consubstanciada nos princípios do SUS, sobretudo nos da universalidade, da integralidade e da participação popular, ao lermos suas disposições chegamos a conclusão do quanto a atenção primária teria que passar por elevados investimentos para dar conta do que está formalmente estabelecido

17 O SUS organizou a atenção à saúde de forma hierarquizada, em níveis crescentes de complexidade. Segundo essa lógica, os serviços de saúde são classificados nos níveis primário, secundário e terciário de atenção, conforme o grau de complexidade tecnológica requerida aos procedimentos realizados. A imagem associada a essa hierarquização é a de uma pirâmide, em cuja base se encontram os serviços de menor complexidade e maior frequência, que funcionariam como a porta de entrada para o sistema. No meio da pirâmide, estão os serviços de complexidade média e alta, aos quais o acesso se dá por encaminhamento e, finalmente, no topo, estão os serviços de alta complexidade, fortemente especializados (MATTA, MOROSINE,2008, p. 42).

${ }^{18}$ A Portaria no 648/GM de 28 de março de 2006 define a atenção básica como um conjunto de ações de saúde no âmbito individual e coletivo que abrangem a promoção e proteção da saúde, prevenção de agravos, diagnóstico, tratamento, reabilitação e manutenção da saúde. É desenvolvida através do exercício de práticas gerenciais e sanitárias democráticas e participativas, sob a forma de trabalho em equipe, dirigidas a populações de territórios bem delimitados pelas quais assume a responsabilidade sanitária, considerando a dinamicidade existente no território em que vivem essas populações. Utiliza tecnologias de elevada complexidade e baixa densidade que devem resolver os problemas de saúde de maior frequência e relevância em seu território. E o contato preferencial dos usuários com os sistemas de saúde. Orienta-se pelos princípios da universalidade, acessibilidade e coordenação do cuidado, vínculo e continuidade, integralidade, responsabilização, humanização, equidade, e participação social (BRASIL, 2006). 
em seu conteúdo e do quanto a formação dos trabalhadores da saúde necessita estar voltada para as necessidades desse nível de atenção.

Na nossa vivência cotidiana com os trabalhadores da saúde seguidamente nos deparamos com a incompreensão por parte desses da dinâmica de gestão dos mecanismos de conexões que cabe aos níveis de atenção à saúde realizar e dos caminhos de integração por meio da referência e contra referência, de linhas de cuidado e de apoio matricial, ${ }^{19}$ que o sistema requer para funcionar a partir do princípio da integralidade.

A integralidade como princípio orientador da formação em saúde, da gestão, da atenção e do controle social ainda é discursivo, embora existam esforços dos atuais sanitaristas ${ }^{20}$ que buscam na articulação desses eixos o fortalecimento e afirmação do sistema em todos os níveis, sobretudo o de sua porta de entrada. Nessa direção a transformação da organização dos serviços e da formação dos trabalhadores da saúde "implicaria trabalho articulado entre o sistema de saúde (em suas várias esferas de gestão) e as instituições formadoras" (CECCIM, FEUERWERKER, 2004, p. 45).

\footnotetext{
${ }^{19}$ Referência constitui "o ato de encaminhamento de um paciente atendido em um determinado estabelecimento de saúde a outro de maior complexidade. A referência deverá sempre ser feita após a constatação de insuficiência de capacidade resolutiva e segundo normas e mecanismos preestabelecidos. O encaminhamento deverá ser acompanhado com todas as informações necessárias ao atendimento do paciente (formulário com resumo da história clínica, resultado de exames realizados, suposição diagnóstica, etc.) e a garantia, através de agendamento prévio, do atendimento na unidade para o qual foi encaminhado. Contra referência constitui "o ato de encaminhamento de um paciente ao estabelecimento de origem (que o referiu) após a resolução da causa responsável pela referência [..], deverá sempre ser acompanhada das informações necessárias ao seguimento ou acompanhamento do paciente no estabelecimento de origem onde, juntamente com seus familiares, será atendido nas suas necessidades básicas de saúde". Disponível em: http://www.fasi.edu.br/files/biblioteca/nut/ABC_sus.pdf, acessado em 01-09-13.

Apoio Matricial: A equipe de referência pede apoio não só a especialistas, mas a profissionais que estão próximos ao usuário no sentido de que são capazes de perceberem aspectos da vida do usuário que podem auxiliar sobremaneira no conjunto das intervenções terapêuticas mais apropriadas. Essa ação se dá pelo apoio matricial que é "uma forma de organizar e ampliar a oferta de ações em saúde, que lança mão de saberes e práticas especializadas, sem que o usuário deixe de ser paciente da equipe de referência" Disponível em: http://bvsms.saude.gov.br/bvs/publicacoes/equipe_referencia.pdf, acessado em 01-09-13.

Linha de cuidado é uma ferramenta pedagógica, entre outras, para dar concretude ao princípio da integralidade. Seria o itinerário que o usuário realiza na rede de saúde, os fluxos assistenciais necessários para atender às necessidades do usuário, incluindo outros caminhos que podem não estar inseridos no sistema de saúde, mas que fazem parte de algum modo da rede.

20 Utilizo as expressões "atuais sanitaristas" no sentido de identificar os trabalhadores da saúde que inspirados nas proposições da RSB vem revitalizando seus sentidos na literatura sobre a materialidade do SUS, além de se constituírem como defensores do sistema tendo por base o revigoramento do ideário da RSB acrescido por inovações e adequações necessárias a atual conjuntura.
} 
$\mathrm{Na}$ realidade, o princípio da integralidade do sistema está longe de uma prática que conecte os segmentos: ensino, gestão, atenção e controle social. Ceccim e Feuerwerker interpretam essas conexões por meio do conceito do "quadrilátero da formação para a área da saúde" que seria a

Construção e organização de uma gestão da educação na saúde integrante da gestão do sistema de saúde, redimensionando a imagem dos serviços como gestão e atenção em saúde e valorizando o controle social (CECCIM; FEUERWERKER 2004b, p. 41).

Com base nos argumentos acima, é importante referirmos que o conceito ampliado de saúde vai demandar uma nova concepção de educação que forme os trabalhadores para além da compreensão de suas atribuições junto à equipe de saúde, mas, sobretudo, para que sejam protagonistas na gestão do sistema, realizando as intervenções na sua organização e atuando no seu controle. A formação em saúde é condição para "qualificar a intervenção dos trabalhadores na definição e organização do sistema de saúde, aliando com isso, a dimensão técnica e a dimensão política na formação dos futuros dirigentes do sistema" (LIMA, 2007, p. 3).

Nesse movimento observamos pelos relatos dos sujeitos da pesquisa que a maioria quase absoluta não teve oportunidade de aprender a historicidade dos movimentos na área da saúde que culminaram na RSB, as questões conjunturais e estruturais que produziram as bases para a criação do sistema, os fundamentos e princípios balizadores que o organizam, suas contradições, avanços e dificuldades, conforme as narrativas a seguir:

Residente farmacêutico - Não tínhamos nada sobre o SUS. Eu não fui preparado para atuar seguindo os princípios do SUS. Nós tivemos disciplinas de deontologia, na qual nos foi colocado como funciona o SUS, só que não nos falaram: "vocês devem atuar assim". Nunca fomos estimulados a atuar como profissionais no SUS. As outras disciplinas não abordavam nada do SUS. Eu concluí o curso em 2009/02.

Preceptor enfermeiro - $\mathrm{Na}$ graduação em enfermagem tive disciplinas em que o enfoque principal era a formalidade, a rigidez no cuidado, não a compreensão do SUS.

Sobre essas questões Martins alerta que as universidades não vêm atendendo aos princípios político-pedagógicos projetados nas DCN, assinalando 
que os avanços nesse sentido são, acentuadamente, tímidos e, ainda que a inserção de mudanças, por meio de práticas de integração docente assistenciais, venha se efetivando nos currículos formais das graduações em saúde, estas continuam batendo de frente com a rigidez dos currículos tradicionais. Assevera que um dos entraves para as propostas de mudança na formação é "o processo de capitalização do setor da saúde”. (MARTINS, 2006, p.112). Acrescentamos que também essa situação se configura em hospitais públicos. Nesse sentido as narrativas dos sujeitos não deixam dúvidas.

Preceptor psicólogo - Nem a minha graduação, nem os cursos de pós que eu fiz contribuíram para o entendimento do SUS. Eu só fui ter uma ideia do sistema bem recentemente, quando começou a existir uma maior abertura no hospital público para isso.

Preceptor nutricionista - Na graduação não tinha essa questão da compreensão das conexões do hospital com a rede, do trabalho em equipe. $\mathrm{Na}$ especialização o enfoque também foi puramente clínico.

Residente farmacêutico - A faculdade de farmácia oferece estágios aqui no Hospital, na Farmácia Popular do Brasil e na Unidade Básica de Saúde. Eu queria ter feito o meu estágio curricular no hospital, mas por falta de vaga acabei optando por uma Unidade Básica.

Residente nutricionista - Durante os estágios junto às equipes não se trabalhava a partir dos princípios do SUS, porque no Hospital público onde fiz o estágio não tinha round multidisciplinar na equipe que eu estava. A gente não interagia com 0 residente médico. Era tudo desconexo.

Residente psicólogo - A minha escolha de campo de estágio foi pelas questões técnicas da psicologia, nunca foi pelo SUS.

A tendência do distanciamento da academia de práticas políticopedagógicas que deem sustentabilidade para atuação no SUS, numa lógica que contrarie as práticas hegemônicas do trabalho em saúde, tem sido uma constante. Nas narrativas acima observamos que nas falas dos preceptores de psicologia e de nutrição essa tendência observada na graduação se estendeu para a pós-graduação. Tais aspectos potencializam as dificuldades de atuação dos trabalhadores, como formadores na residência multiprofissional em saúde. 


\section{Considerações Finais}

As graduações em saúde, realizadas pelos preceptores e residentes do Programa de Residência Multiprofissional, resultaram em formações, ora demasiadamente reprodutoras da lógica cartesiana, positivista e fragmentária, ora produtoras de formações que se aproximaram do ideário dos princípios e diretrizes do SUS.

O Programa de Residência pesquisado, pensado para propiciar um caminho de formação multiprofissional integrado, quando praticado por seus sujeitos, mediado por suas formações iniciais e continuadas ficou limitado em suas respectivas propostas, conforme a eloquência das falas dos entrevistados.

A formação inicial e a formação continuada, tanto dos preceptores como dos residentes, embora o lapso de tempo entre essas e as mudanças veiculadas nas atuais Diretrizes Nacionais da formação em saúde, não se diferenciaram, resultando em práticas de formação e de trabalho ainda distantes dos objetivos propostos no Programa de Residência em tela. Entretanto, foi observado que a formação em serviço promovida no programa tem estimulado os profissionais envolvidos a repensarem práticas que expressem a realização do trabalho integrado em saúde.

A Residência Multiprofissional é um caminho, os programas PET Saúde e Pró Saúde também, os caminhos de formação permanente dos trabalhadores nas instituições, as rodas de conversa sobre trabalho, problematizando conceitos ampliados de educação e saúde, constituem também espaços de reflexão-açãoreflexão que podem produzir frutos saudáveis na busca de uma base social/material sustentável na defesa e fortalecimento do SUS.

Embora a base positivista e cartesiana do individualismo empírico persista na formação dos profissionais da saúde, já observamos por dentro dessa, rupturas no sentido de uma formação que vai se preparando para o Sistema Único de Saúde, na perspectiva de seus princípios ético-políticos e da própria complexidade da atenção em saúde. 


\section{Referências Bibliográficas}

ALBERTI, Verena. Manual de História Oral. Rio de Janeiro: FGV, 2001.

AGUIAR, S. R.; NERY, E.; PEIXOTO, M. T. PET-saúde da família, uma experiência interdisciplinar no cenário de prática das unidades de saúde da família - Feira de Santana-BA. In: SEMINÁRIO DE INICIAÇÃO CIENTÍFICA DA UNIVERSIDADE ESTADUAL DE FEIRA DE SANTANA, 14, Feira de Santana, 18 a 22 de outubro de 2010. Anais.

BRASIL. Lei 8.080 de 19 de setembro de 1990. Dispõe sobre as condições para a promoção, proteção e recuperação da saúde, a organização e o funcionamento dos serviços correspondentes e dá outras providências. Disponível em:

$<$ http://portal.saude.gov.br/portal/arquivos/pdf/LEl8.080.pdf.> Acessado em 22/11/2009.

BRASIL. Lei 11.129 de 30 de junho de 2005. Programa Nacional de Inclusão de Jovens ProJovem; cria o Conselho Nacional da Juventude - CNJ e a Secretaria Nacional de Juventude; altera as Leis nos 10.683 , de 28 de maio de 2003, e 10.429, de 24 de abril de 2002; e dá outras providências. Disponível em: <http://www.planalto.gov.br/CCIVIL_03/_Ato2004-2006/2005/Lei/L11129.htm.> Acessado em 22/11/2009.

BRASIL. Constituição (1988). Constituição da República Federativa do Brasil. Brasília, DF: Senado, 1988.

BRASIL. Diretrizes curriculares nacionais para a formação de professores da educação básica, em nível superior, curso de licenciatura, de graduação plena. Parecer: CNE/CP 009/2001. Brasília, DF, 2001.

BRASIL. Parecer CNE/CEB № 1.133/2001. Diretrizes Curriculares Nacionais do Curso de Graduação em Enfermagem, Medicina e Nutrição. Disponível em: <http://portal.mec.gov.br/cne/arquivos/pdf/CES1133.pdf.> Acessado em: 22/11/2009.

BRASIL. Ministério da Saúde. Política Nacional de Atenção Básica. Portaria no 648 de 28 de março de 2006. Brasília, v. 143, n.61, 2006. Seção 1, p. 71-76.

CAPONI, S. A proposito del concepto de salud. Florianópolis: UFSC, 1997.

CECCIM, Ricardo Burg e FEUERWERKER, Laura C. Macruz. Mudança na graduação das profissões de saúde sob o eixo da integralidade. Cad. Saúde Pública [online]. 2004a, vol. 20, n. 5, pp. 1400-1410. ISSN 0102-311X. Disponível em: <http://dx.doi.org/10.1590/S0102-311X2004000500036.> Acessado em: 09/6/2013

.Ricardo Burg e FEUERWERKER, Laura C. M. O quadrilátero da formação para a área da saúde: ensino, gestão, atenção e controle social. Physis [online]. 2004b, v. 14, n. 1, pp. 41-65. ISSN 0103-7331. 
COUTINHO, Carlos Nelson. Resenha [prefácio]. In: NEVES, Lúcia Maria Wanderley. A nova pedagogia da hegemonia: estratégias do capital para educar o consenso. São Paulo: Xamã, 2005.

COUTO, Berenice Rojas. As diretrizes curriculares e a política social. In: Revista Temporalis. №. 8. Ano IV. Porto Alegre: ABEPSS, 2004.

DEJOURS, C. Por um novo conceito de saúde. Revista Brasileira de Saúde Ocupacional, São Paulo, v. 14, n. 54, p. 7-11, abr./ jun.1986.

ENGELS, Friedrich. Do Socialismo Utópico ao Socialismo Científico. Tradução Roberto Goldkorn. 4aㅡ ed. São Paulo, Global Editora, 1981.

FERREIRA, Aurélio B. de Hollanda. O Dicionário da Língua Portuguesa. Edição Especial. Curitiba: Positivo, 2008. $544 p$

FREIRE, Paulo. Pedagogia da Autonomia. São Paulo. Paz e Terra. 1996.

FRIGOTTO, Gaudêncio. Anos 1980 e 1990: A Relação entre o estrutural e o conjuntural e as políticas de educação tecnológica e profissional. In: FRIGOTTO, Gaudêncio; CIAVATTA, Maria. A Formação do Cidadão Produtivo: A Cultura de Mercado no Ensino Médio Técnico. Brasília, INEP, 2006.

.Gaudêncio. Resenha [contracapa]. In: MATTA, Gustavo Corrêa; LIMA, Júlio César França (Orgs.). Estado, Sociedade e Formação Profissional em Saúde: contradições e desafios em 20 anos de SUS. Rio de Janeiro, Fiocruz/EPSJV, 2008. [s.p.].

GRAMSCI, Antonio. Cadernos do Cárcere. Rio de Janeiro, v.5. Civilização Brasileira, 2002.

. Cadernos do Cárcere. Rio de Janeiro: Civilização Brasileira, 2000. v. 3

ITO, Elaine Emi. et al. $O$ ensino de enfermagem e as diretrizes curriculares nacionais: utopia x realidade. São Paulo, Rev. Esc. Enferm. USP, v. 40, n. 4 p. 570-5, 2006. Disponível em: <www.ee.usp.br/reeusp.> Acessado em 05/06/2007.

LIMA, Júlio César França. Neoliberalismo e Formação Profissional em Saúde. Revista Eletrônica do Neddate - Núcleo de Estudos, Documentação e Dados em Trabalho e Educação do Programa de Pós-Graduação em Educação da Universidade Federal Fluminense, Ano 5, № 5-2007. Disponível em:

<http://www.uff.br/trabalhonecessario/TN5\%20LIMA,\%20J.C.F..pdf. Acessado em 24/10/2010.

LUNARDI, Valéria Lerch. Problematizando conceitos de saúde, a partir do tema da governabilidade dos sujeitos. In: Revista Gaúcha de Enfermagem, Porto Alegre, v.20, n.1, p.26-40, jan. 1999.

MARTINS. Maria Cezira Fantini Nogueira. Formação: Saberes e Fazeres Humanizados. In: Boletim da Saúde/ Secretaria do Estado da Saúde do Rio 
Grande do Sul; Escola de Saúde Pública. v. 20, n. 2, 2006, Porto Alegre: SES/ESP, 1969 - Semestral ISSN- 0102 -1001.

MACIEL, Ana Lúcia Suarez. Universidade em crise: uma travessia necessária para a formação em Serviço Social. Tese de Doutorado. Porto Alegre: PUCRS, 2006.

MATTA, Gustavo Correa; MOROSINE, Márcia Valéria Guimarães. Atenção Primária à Saúde. In: PEREIRA, Isabel Brasil; LIMA, Júlio Cesar França (Orgs.). Dicionário da educação profissional em saúde, 2 ed. rev. ampl. - Rio de Janeiro: EPSJV, 2008.

MELO, Adriana Almeida Sales de. A mundialização educação: consolidação do projeto neoliberal na América Latina, Brasil e Venezuela. Maceió: EDUFAL, 2004.

MEIHY, José Carlos S. Bom. Manual de História Oral. São Paulo: Loyola, 1996.

PUSTAI, Odalci José. A "ordem" de vida para o médico pensar o paciente: Uma Ontologia Espinosana do ser humano na medicina. Tese de Doutorado na FACED/ UFRGS. Porto Alegre, 2006.

TRIVIÑOS. Augusto Nibaldo. Bases Teórico-Metodológicas na Pesquisa Qualitativa em Ciências Sociais. Porto Alegre: Ritter dos Reis, 2001.

Recebido em: 08 de setembro de 2017. Aprovado em: 10 de janeiro de 2018. Publicado em: 31 de janeiro de 2018. 